\title{
Esophageal Button Batteries
}

\section{Veereshwar Bhatnagar ${ }^{1,2}$}

Received: 1 June 2020 / Accepted: 1 June 2020 / Published online: 30 June 2020

(C) Dr. K C Chaudhuri Foundation 2020

While discussing ingested button batteries (BB), it is true that the majority of the BBs lodge in the esophagus and cause chemical injuries which in turn have the potential to cause severe morbidity and mortality. However, some do pass beyond the esophagus and can result in gastric or intestinal injuries.

In this issue of Indian Journal of Pediatrics Anand et al. describes the experience in managing a cohort of 52 children with BB ingestion over a period of $5 \mathrm{y}$ [1]. The authors have restricted the paper to just esophageal BBs. This paper would have been more comprehensive if they had also included BBs which had passed beyond the esophagus. However, the management of esophageal BBs has been described and discussed well.

The authors have referred to a very detailed article by Leinwad $\mathrm{K}$ et al. [2]. In this article 13 cases with complications have been described and lessons learnt from each case have been summarized. In addition to what the authors [2] have discussed, various other aspects have also been highlighted. Notable among these are:

i) The BB has a propensity to adhere to the esophageal mucosa.

ii) An exposure of even $2.5 \mathrm{~h}$ can lead to enough tissue destruction to cause a tracheo-esophageal fistula (TEF).

iii) Despite minimal findings of edema/ulceration more severe injury can evolve,

iv) Despite a reassuring esophagogram and clinical stability, an aortoesophageal fistula can occur.

v) Even if the BB has passed into the stomach, a severe esophageal injury can manifest.

Veereshwar Bhatnagar

veereshwarb@hotmail.com

1 Department of Pediatric Surgery, School of Medical Sciences \& Research, Sharda University, Greater Noida, UP, India

2 Department of Pediatric Surgery, AIIMS, New Delhi, India vi) Acute hematemesis in otherwise health toddlers should lead to a suspicion of previous BB ingestion.

vii) Respiratory symptoms should alert to the possibility of vocal cord or tracheal injury, either or both of which can be a cause of morbidity and mortality, and.

viii) MRI should be part of the protocol for evaluation of extent of injury.

MRI, as a modality for assessing the extent of injury and possibly predicting fistulisation of the esophagus with the trachea or the aorta, is reportedly routinely practiced in the post extraction period.

In a report from the Netherlands, serious complications have also been caused by small batteries $(<20 \mathrm{~mm})$ and in children who were asymptomatic to begin with [3].

Children younger than 6 y have been reported to be most prone to BB ingestion, with lithium batteries and are often associated with complications [4].

There are no established guidelines for BBs which go past the esophagus. There are recommendations to allow it to pass out per rectally. On the other hand, severe injuries to the stomach have been reported and magnetic forceps are used for extraction from the stomach [5].

The National Capital Poison Center has prepared a very comprehensive algorithm for triage and treatment guidelines for BB ingestion. This also includes management of button batteries which go past the esophagus. The discerning reader should refer to this very detailed algorithm [6].

\section{Compliance with Ethical Standards}

Conflict of Interest None.

\section{References}

1. Anand S, Jain V, Agarwala S, Dhua AK, Yadav DK. Esophageal button battery in the pediatric population: experience from a tertiary 
care center. Indian J Pediatr. 2020. https://doi.org/10.1007/s12098020-03222-1.

2. Leinwad K, Brumbaugh DE, Kramer RE. Button battery ingestion in children. A paradigm for management of severe pediatric foreign body ingestions. Gastrointest Endosc Clin N Am. 2016;26:99-118.

3. Krom H, Visser M, Hulst JM, et al. Serious complications after button battery ingestion in children. Eur J Pediatr. 2018;177:106370 .

4. Varga Á, Kovács T, Saxena AK. Analysis of complications after button battery ingestion in children. Pediatr Emerg Care. 2018;34: 443-6.
5. Khalaf RT, Ruan W, Orkin S, et al. Gastric injury secondary to button battery ingestions: a retrospective multicenter review. Gastrointest Endosc. 2020;S0016-5107(20):34191-2. https://doi. org/10.1016/j.gie.2020.04.037.

6. National Capital Poison Center. Button battery ingestion triage and treatment guidelines 2010-2020. Available at: https://www.poison. org/battery/guidelines.

Publisher's Note Springer Nature remains neutral with regard to jurisdictional claims in published maps and institutional affiliations. 